\title{
Uterine pseudoaneurysm on the basis of deep infiltrating endometriosis during pregnancy-a case report
}

\author{
Tibor Andrea Zwimpfer ${ }^{1,2^{*}}$ (D), Cécile Monod ${ }^{1}$, Katharina Redling ${ }^{1}$, Heike Willi ${ }^{1}$, Martin Takes ${ }^{3}$, \\ Bernhard Fellmann-Fischer ${ }^{1}$, Gwendolin Manegold-Brauer ${ }^{1}$ and Irene Hösli ${ }^{1}$
}

\begin{abstract}
Background: Pseudoaneurysm of the uterine artery (UPA) is a rare cause of potentially life-threatening hemorrhage during pregnancy and puerperium. It is an uncommon condition that mainly occurs after traumatic injury to a vessel following pelvic surgical intervention, but also has been reported based on underlying endometriosis. There is an increased risk of developing UPA during pregnancy. Diagnosis includes clinical symptoms, with severe abdominal pain and is confirmed by sonographic or magnetic resonance imaging (MRI). Due to its potential risk of rupture, with a subsequent hypovolemic maternal shock and high fetal mortality, an interdisciplinary treatment should be considered expeditiously.

Case presentation: We present the case of a 34-year old pregnant symptomatic patient, where a large UPA was detected at 26 weeks, based on deep infiltrating endometriosis (DIE). The UPA was successfully treated by selective arterial embolization. After embolization, the pain decreased but the woman still required intravenous analgesics during follow-up. At 37 weeks she developed a sepsis from the intravenous catheter which led to a cesarean section and delivery of a healthy boy. She was discharged 10 days postpartum.

Conclusions: UPA should be considered in pregnant women with severe abdominal and pelvic pain, once other obstetrical factors have been excluded. DIE might be the underlying diagnosis. It is a rare but potentially lifethreatening condition for mother and fetus.
\end{abstract}

Keywords: Uterine pseudoaneurysm, Deep infiltrating endometriosis, Pregnancy

\section{Background}

Uterine pseudoaneurysm (UPA) is a condition in which the arterial vessel wall has lost intraluminal continuity and blood accumulates between the two outer layers of the artery. It can present with severe abdominal and pelvic pain, and sonographic imaging or magnet resonance imaging (MRI) can detect a pulsatile growing mass. UPA

\footnotetext{
* Correspondence: tibor.zwimpfer@unibas.ch

'Department of Obstetrics and Gynecology, University Hospital of Basel, Basel, Switzerland

${ }^{2}$ Department of Biomedicine, University Hospital of Basel and University Basel, Basel, Switzerland

Full list of author information is available at the end of the article
}

occurs mainly after a traumatic injury of the vessel following pelvic surgical intervention, but rarely, it is based on severe endometriosis as DIE (Deep infiltrating endometriosis) [1-5]. The main causes are gynecological interventions, such a myomectomy, treatment of endometriosis, ovarian puncture or cystectomies, and obstetrical interventions, such as cesarean section, curettage, and vacuum or forceps extraction [3-9]. Furthermore, there is an increased risk of developing UPA during pregnancy.

Due to the potential risk of rupture, with subsequent hypovolemic shock of the mother and a high fetal mortality, the diagnosis of UPA in pregnancy requires urgent

(C) The Author(s). 2021 Open Access This article is licensed under a Creative Commons Attribution 4.0 International License, which permits use, sharing, adaptation, distribution and reproduction in any medium or format, as long as you give appropriate credit to the original author(s) and the source, provide a link to the Creative Commons licence, and indicate if changes were made. The images or other third party material in this article are included in the article's Creative Commons licence, unless indicated otherwise in a credit line to the material. If material is not included in the article's Creative Commons licence and your intended use is not permitted by statutory regulation or exceeds the permitted use, you will need to obtain permission directly from the copyright holder. To view a copy of this licence, visit http://creativecommons.org/licenses/by/4.0/ The Creative Commons Public Domain Dedication waiver (http://creativecommons.org/publicdomain/zero/1.0/) applies to the data made available in this article, unless otherwise stated in a credit line to the data. 
interdisciplinary treatment. The standard of care is a selective arterial embolization of the uterine artery by the interventional radiologist, which has a good risk-benefit profile $[10,11]$.

Here, we present the observation of a pregnant patient with a successfully treated symptomatic UPA that occurred in the second trimester, on the basis of a DIE in the left uterine artery and cervix.

\section{Case presentation}

The 34-year old, first gravida, was admitted to our obstetrical department by ambulance at $23+0$ weeks of gestation (WG) with progressive severe pain over $24 \mathrm{~h}$ in the left lower abdomen irradiating to the rectum and the vagina. The previous day, she had an unremarkable clinical and sonographic examination and a normal laboratory investigation. Her past medical history included a conization due to cervical dysplasia, dysmenorrhea and dyspareunia with suspected endometriosis, and the use of a combined oral contraceptive for 16 years prior to the current pregnancy. The pregnancy occurred spontaneously, with a single fetus. The otherwise healthy patient showed pain on palpation in the two lower abdominal quadrants: speculum examination revealed cervical ectopy and two black dots were visible at six o'clock. The vital signs were normal with an unremarkable pulse, respiratory rate, body temperature, blood pressure, and the hemoglobin was stable at $129 \mathrm{~g} / \mathrm{l}$. The laboratory tests and urine analysis showed no signs of infection. The cardiotocogram (CTG) was normal without contractions. Cervical length was $34 \mathrm{~mm}$, measured by transvaginal ultrasound. Fetal sonography and Doppler studies revealed normal biometry with a fetus appropriate for gestational age at 42nd percentile, normal amniotic fluid, a posterior wall placenta without signs of hematoma and a normal uteroplacental resistance. Caudal and adjacent to the left ovary, a solid, ill-defined adnexal mass of $40 \times 45 \mathrm{~mm}$ and moderate blood flow was detected (Fig. 1 a, b). On MRI, the adnexal mass was seen and was suggestive of endometriosis (Fig. 2 a and b). There were no signs of intraabdominal free fluid or kidney stones.
A.

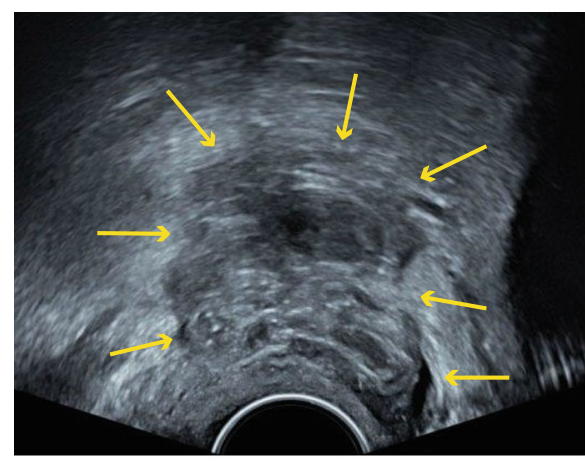

c.

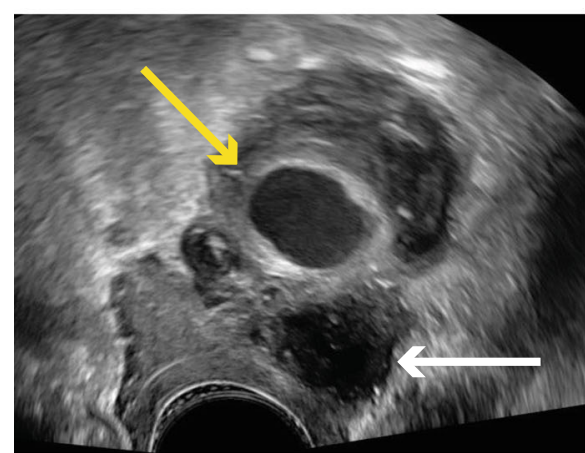

B.

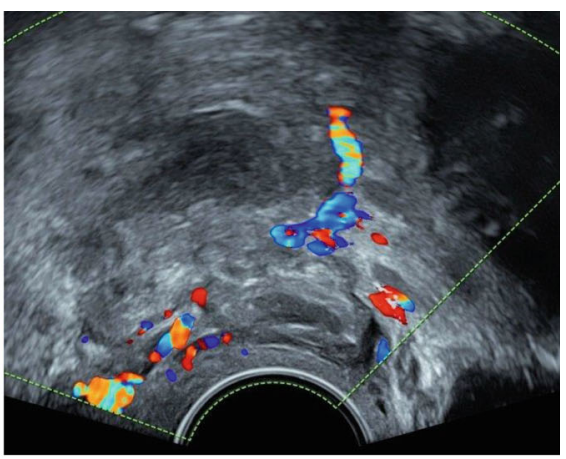

D.

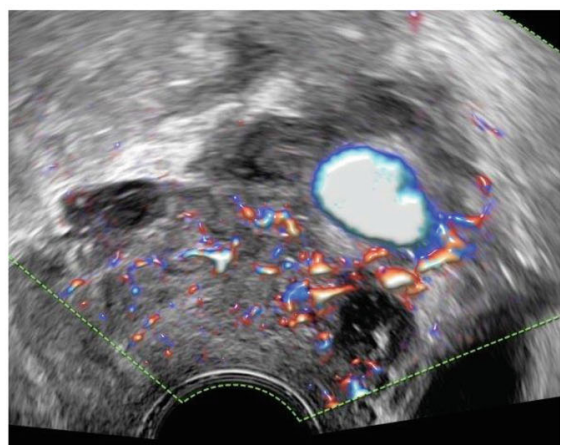

Fig. 1 Development of the UPA over 2 weeks by ultrasound. Visit 1 with a. Ultrasound image of the ill-defined solid mass in the adnex at the initial presentation at $23+2$ gestational weeks. The arrows mark the outer margins of the lesion. An endometrioma is not clearly visible. $\mathbf{b}$. Corresponding Doppler image of the left adnexa showing moderate blood flow (Color Score 3 ) in the lesion. Visit 2 with cUltrasound Image of the same lesion on the follow up at $25+2$ gestational weeks. On the lower right there is an unilocular mass suggestive of endometrioma. In the center there is a pulsating vessel (UPA) of about $2 \mathrm{~cm}$ with most likely haematoma surrounding the UPA and $\mathbf{d}$. corresponding Doppler image confirming blood flow in the vessel. 


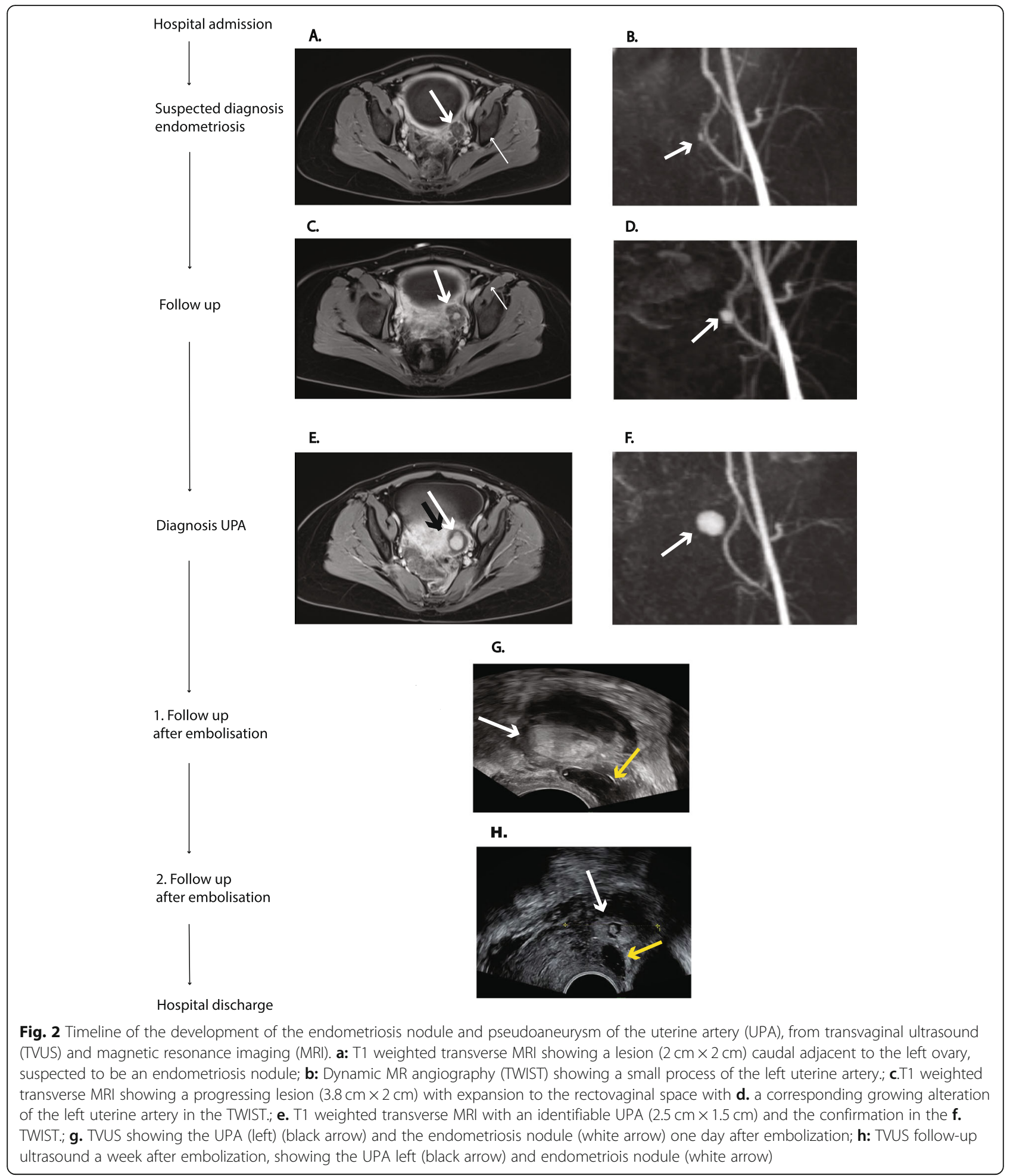

The patient was hospitalized for monitoring and analgesic therapy. The pelvic pain persisted despite intravenous (IV) opiate therapy. Additionally, the patient complained of newly occurring dyschezia and a single episode of brown vaginal discharge. A follow-up MRI after 6 days, at $24+1$ WG showed progression of the lesion, with expansion into the rectovaginal space (Fig. $2 \mathrm{c}$ and $\mathrm{d}$ ). The patient remained hospitalized for maternal and fetal monitoring and received continuous analgesia and steroids for fetal lung maturation induction with 
tocolysis as a precautionary measure. Sixteen days after hospitalization $(25+3 \mathrm{WG})$, a pseudoaneurysm of the left uterine artery $(2.5 \mathrm{~cm} \times 1.5 \mathrm{~cm})$ was identified by ultrasound (Fig. $1 \mathrm{c}$ and d) and confirmed by MRI. (Fig. 2 e and f). An interdisciplinary team of radiologist, fetomaternal specialists, gynecologists and neonatologists concluded that, based on the early gestational age, the progression of the lesion and in view to the persistent pain, a selective embolization of the left uterine artery would be the preferred management. The neonatologist team was prepared for an emergency cesarean section in case of any complications. The intervention was carried out under local anesthesia with a retrograde access over the left common femoral artery. No digital subtraction angiography was performed in order to minimize radiation exposition. Embolization was achieved by selective occlusion of the aneurysm-feeding branch of the left uterine artery over a microcatheter by injection of $0.2 \mathrm{ml}$ liquid embolic material (histoacryl/lipiodol 1:3). The estimated radiation exposure for the uterus was $0.4 \mathrm{mSv}$. Subsequently the contrast media had suspended in the UPA as indication for a sufficient occlusion. Further sequential sonographic examinations confirmed normal fetal growth and Doppler flow. The embolized UPA showed no vascularization and decreased to $2 \mathrm{~cm} \times 1 \mathrm{~cm}$ on sonography before hospital discharge (Fig. $2 \mathrm{~g}$ and $\mathrm{h}$ ). The pelvic pain improved but did not resolve completely and the patient received a peripherally inserted central venous catheter (PICC) line and, temporarily, a patientcontrolled analgesia pump. After 30 days $(28+2 \mathrm{WG})$, she was discharged to outpatient care with oral morphine in reserve and the PICC line in situ. A primary cesarean at 38 weeks was planned because of the risk of the UPA rupturing during contractions. However, the patient presented herself at 37 weeks, with sepsis of unknown etiology, a fever of $39.0^{\circ} \mathrm{C}$, tachypnea, hypotension, maternal tachycardia, a C-reactive protein of $23.8 \mathrm{mg} / \mathrm{l}$ and fetal tachycardia (200 beats per minute). An emergency cesarean delivery was done under general anesthesia with antibiotic therapy (amoxicillin and clavulanic acid) and a healthy boy was born $(2670 \mathrm{~g})$ with Apgar 6/7/8 and pH 7.31. Postoperatively, the patient needed intensive care (IC) for 3 days. Blood cultures were positive for Serratia macescens and Streptococcus anginosus, and according to the resistance tests, treatment was changed to carbapenem IV. The patient was discharged, together with the newborn, 10 days after the cesarean section. The infection was most likely caused by an infected PICC line, even though the results of the smear tests and cultures were unremarkable.

The patient presented for follow-up at 6 weeks postpartum. She had lactation amenorrhea, persisting dyschezia and newly developed hematochezia. Rectovaginal sonography and palpation identified an unchanged endometriosis node. We started suppressive therapy with Desogestrel and scheduled a colonoscopy to exclude another origin for the hematochezia and an MRI for staging. The MRI showed an endometriosis node $3 \times 2 \mathrm{~cm}$ adjacent to the septum rectovaginale with expansion to the left ovary and in close proximity to the sigmoid without infiltration according to an Enzian score A2, B1, C1. (Fig. 3 a and b) The restructuring operation of the symptomatic DIE is planned for 4 months after her delivery.

\section{Discussion}

This case illustrates the difficulty to diagnose the rare entity of a UPA during pregnancy. In our case, the appearance of the lesion changed over time and finally led to the correct diagnosis with the combination of sonography and MRI. There is an increased risk of developing or diagnosing UPA during pregnancy. It is assumed that the physiological changes of the hormonal milieu and cardiovascular system, together with the pressure on the vessels promote the development of UPA [12]. Additionally, the improvement of imaging technology and the frequent ultrasounds during pregnancy increase the probability of diagnosing a UPA.

Endometriosis further increases the risk of UPA during and after pregnancy, in particular DIE [13-15]. The endometrial implants demonstrate a non-location response to hormonal stimulation. Estrogens are a proliferating factor, and the hormone withdrawal results in abortive bleeding which is associated with pain. Additionally, inflammatory cell production is stimulated, resulting in pain and adhesions. Gestagen inhibits the inflammatory reaction. In menopause, the decline of ovarian stimulation turns active endometriosis lesions inactive. Since pregnancy has a similar effect, with a decline of ovarian stimulation and increasing gestagen levels, a common assumption is that pregnancy temporarily cures endometriosis [16-18]. Recently, conflicting data demonstrates preexisting endometriosis causes pregnancy complications due to adhesions, chronic inflammation and intrusion of decidualized endometriosis [19-21]. Chronic inflammation makes the vessels more vulnerable to lacerations [22] and adhesion can increase the stress on uterine-ovarian vessels [23]. The intrusion of decidualized endometriosis can result in a perforation of the uterine-ovarian vessels and, because of persistent progesterone levels, decidualization occurs with differentiation of mesenchymal cells $[24,25]$. A decrease in progesterone at the end of the third trimester of pregnancy correlates with an increased expression of inflammatory cells, proteolytic degradation of the extracellular matrix, cell death, and, finally, bleeding of the peritoneum $[26,27]$. 
A.

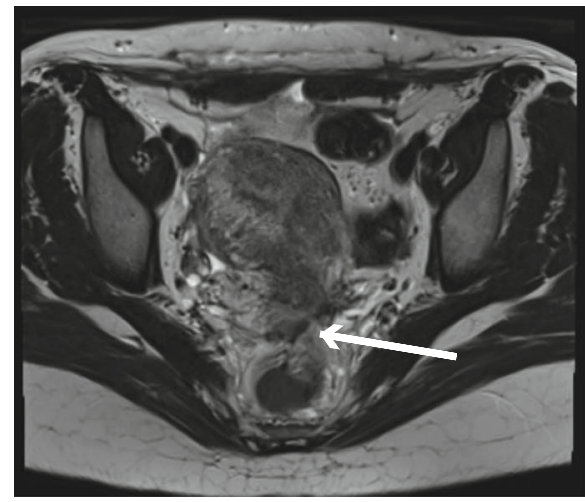

B.

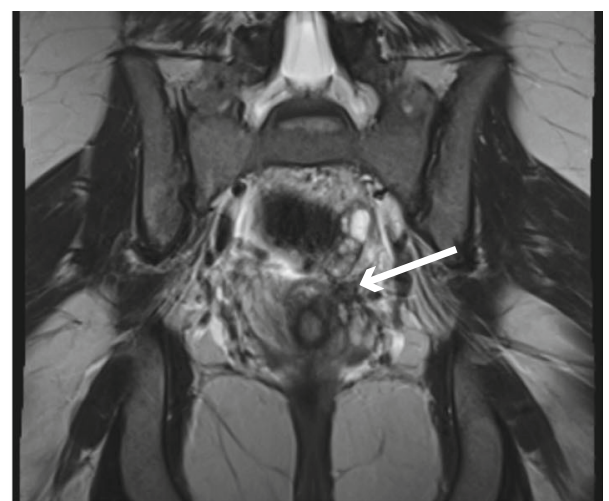

Fig. 3 Abdominal magnetic resonance imaging (MRI) two months after the delivery a. T2 weighted transverse MRI and $\mathbf{b}$. T2 weighted coronal MRI showed an endometriosis node $3 \times 2 \mathrm{~cm}$ (white arrow) adjacent to the septum rectovaginale with expansion to the left ovary and in close proximity to the sigmoid without infiltration according to an Enzian score A2, B1, C1

In this patient, the combination of preexisting DIE and pregnancy probably caused the UPA. The close followup, with ultrasound and MRI, enabled us to detect the development of the UPA from the endometriosis node during the second trimester. Previously, ruptured or unruptured UPA have been detected in pregnant patients with a known history of endometriosis or previous surgery [13-15]. Van Coppenollea et al. summarized six cases of UPA, based on previous appendectomy, cesarean section or surgically treated endometriosis [9]. Feld et al. described even a case of a hemoperitoneum, caused by a ruptured UPA based on endometriosis, but the UPA was only detected postpartum [13]. Our patient was symptom-free apart from occasional dyspareunia and dysmenorrhea because of a suspected rectovaginal endometriosis before pregnancy, as she was on hormonal contraception for 16 years until 6 months before pregnancy. We presume that the pregnancy stimulated the decidualization of the endometriosis, in particular of the deep infiltrating rectovaginal node adjacent to the UPA. The chronic inflammation, in combination with the decidualization, might have increased the stress on the uterine artery resulting in the UPA. Fortunately, the UPA was diagnosed early, and the expedited treatment preserved the pregnancy and avoided preterm delivery.

Transcatheter arterial embolization has been established as an effective technique for the management and prevention of obstetric and gynecologic hemorrhage [10, 11, 15, 28-30]. Complications of transcatheter arterial embolization are extremely uncommon when it is performed by expert interventional radiologists. Its advantages include prevention of surgical risks, high success rates, low complication rates, and no significant impact on future pregnancies and fertility [10, 11, 15, 28-30]. Three reported cases in literature $[11,14,30]$ and our case suggest that successful unilateral uterine artery embolization is well tolerated by the fetus and therefore appears to be a safe and effective method to treat pseudoaneurysm during pregnancy without compromising uteroplacental perfusion. Moreover, in our case the estimated radiation exposure for the uterus was only 0.4 $\mathrm{mSv}$, which is far below any critical exposure rate for the fetus.

Our patient suffered long-term from severe immobilizing pain, which was difficult to control. Furthermore, the hospitalization and treatment were physically and emotionally very stressful. This raises the question regarding early diagnosis and treatment of such cases through monitoring pregnancies of patients with endometriosis. Currently, there is no evidence that endometriosis has a significant effect on pregnancy outcome [31, 32].; however, rare cases such as our case might be encountered in pregnancy and a data base of deep infiltrating endometriosis like that available at the Kepler University Clinic together with the Foundation Endometriosis Research (SEF), and with support of the Deutsche Gesellschaft für Gynäkologie und Geburtshilfe (DGGG) will be helpful in identifying patients at risk for such a complication and provide diagnostic and treatment guidelines.

\section{Conclusions}

UPA should be considered in pregnant women with severe abdominal and pelvic pain, once other obstetrical factors have been excluded. Endometriosis can cause UPA during and after pregnancy, in particular DIE. It is a rare but potentially life-threatening condition for the mother and fetus, as a rupture of the UPA will result in hemoperitoneum and hypovolemic, hemorrhagic shock. The standard of care in a stable situation is selective arterial embolization, which has a good risk-benefit profile. There is currently no evidence that endometriosis has a 
harmful effect on the pregnancy outcome, therefore, no special monitoring of conventional pregnancies for patients with endometriosis is required. Nevertheless, awareness should be raised among physicians, and similar cases should be reported to establish treatment guidelines.

\section{Abbreviations}

CTG: Cardiotocogram; DIE: Deep infiltrating endometriosis; IC: Intensive care; IV: Intravenous; MRI: Magnetic resonance imaging; PICC: Peripherally inserted central venous catheter; TVUS: Transvaginal ultrasound; UPA: Uterine pseudoaneurysm; WG: Weeks of gestation

\section{Acknowledgements}

Not applicable.

\section{Authors' contributions}

(I) Conception and design: TZ, KR, HW, GM. (II) Administrative support: IH, BF, GM, MT. (III) Collection and assembly of data: TZ, CM, MT. (IV) Data analysis and interpretation: TZ, CM, KR, HW. (V) Manuscript writing: all authors. (VI) Final approval of manuscript: all authors.

\section{Funding}

Not applicable.

\section{Availability of data and materials}

The data and materials analyzed during the current case report are presented within the manuscript and available from the corresponding author.

\section{Declarations}

\section{Ethics approval and consent to participate}

According to the ethics committee of Northwest and Central Switzerland (EKNZ) the project does not fall under the remit of the cantonal or federal law Human Research Act (HRA) because the project is not defined as a research project as per HRA Art. 2; therefore, an Institutional Review Board approval is not needed. The patient gave her written consent to participate in this case report and waived any claims. The anonymization of personal data was guaranteed.

\section{Consent for publication}

Written informed consent was obtained from the patient for publication of this case report and any accompanying images. A copy of the written consent is available for review by the Editor of this journal.

\section{Competing interests}

The authors Tibor Andrea Zwimpfer, Cécile Monod, Katharina Redling, Heike Willi, Martin Takes, Bernhard Fellmann-Fischer, Gwendolin Manegold-Brauer and Irene Hösli have no competing interest to disclose.

\section{Author details}

${ }^{1}$ Department of Obstetrics and Gynecology, University Hospital of Basel, Basel, Switzerland. ${ }^{2}$ Department of Biomedicine, University Hospital of Basel and University Basel, Basel, Switzerland. ${ }^{3}$ Department of Radiology and Nuclear Medicine, University Hospital of Basel, Basel, Switzerland.

Received: 15 December 2020 Accepted: 24 March 2021

Published online: 09 April 2021

\section{References}

1. Ferrero S, Bogliolo S, Rossi UG, Baldi C, Valenzano Menada M, Ragni N, et al. Unusual complication of excision of pelvic endometriosis: pseudoaneurysm of the left uterine artery. Fertil Steril. 2010;93(1):264-6. https://doi.org/10.101 6/j.fertnstert.2009.02.002

2. Boi L, Savastano S, Beghetto M, Dall'Acqua J, Montenegro GM. Embolization of iatrogenic uterine pseudoaneurysm. Gynecol Minim Invasive Ther. 2017; 6(2):85-8. https://doi.org/10.1016/j.gmit.2017.02.004.

3. Baba Y, Matsubara S, Kuwata T, Ohkuchi A, Usui R, Saruyama M, et al. Uterine artery pseudoaneurysm: not a rare condition occurring after non- traumatic delivery or non-traumatic abortion. Arch Gynecol Obstet. 2014; 290(3):435-40. https://doi.org/10.1007/s00404-014-3226-4.

4. Wald DA. Postpartum hemorrhage resulting from uterine artery pseudoaneurysm. J Emerg Med. 2003;25(1):57-60. https://doi.org/10.1016/ S0736-4679(03)00098-2.

5. Bhatt A, Odujebe $\mathrm{O}$, Bhatt S, Houry D. Uterine artery pseudoaneurysm rupture: a life-threatening presentation of vaginal bleeding. Ann Emerg Med. 2010;55(5):460-3. https://doi.org/10.1016/j.annemergmed.2 010.01.026.

6. Dohan A, Soyer P, Subhani A, Hequet D, Fargeaudou Y, Morel O, et al. Postpartum hemorrhage resulting from pelvic pseudoaneurysm: a retrospective analysis of 588 consecutive cases treated by arterial embolization. Cardiovasc Intervent Radiol. 2013;36(5):1247-55. https://doi. org/10.1007/s00270-013-0668-1.

7. Isono W, Tsutsumi R, Wada-Hiraike O, Fujimoto A, Osuga $Y$, Yano T, et al. Uterine artery pseudoaneurysm after cesarean section: case report and literature review. J Minim Invasive Gynecol. 2010;17(6):687-91. https://doi. org/10.1016/j.jmig.2010.06.004.

8. Matsubara S. Uterine artery pseudoaneurysm after cesarean section: case report and literature review [Letter,author reply]. J Minim Invasive Gynecol. 2011;18:411-2.

9. Van Coppenolle C, Jaillet L, Gallot D, Chabrot P, Delabaere A. Rupture d'un aneuvrisme de l'artere uterine en cours de grossesse traitée par embolisation. Gynecol Obstet Fertil Senol. 2019;47(10):761-4. https://doi. org/10.1016/j.gofs.2019.08.006.

10. Kwon JH, Kim GS. Obstetric iatrogenic arterial injuries of the uterus: diagnosis with US and treatment with transcatheter arterial embolization. Radiographics. 2002;22(1):35-46. https://doi.org/10.1148/radiographics.22.1.g02ja0735.

11. Ugwumadu L, Hayes K, Belli AM, Heenan S, Loftus I. Uterine artery pseudoaneurysm requiring embolization in pregnancy: a case report and review of the literature. CVIR Endovasc. 2018;1(1):31. https://doi.org/10.1186/ s42155-018-0040-2.

12. Barrett JM, Van Hooydonk JE, Boehm FH. Pregnancy-related rupture of arterial aneurysms. Obstet Gynecol Surv. 1982;37(9):557-66. https://doi.org/1 0.1097/00006254-198209000-00001.

13. Feld Z, Rowen T, Callen A, Goldstein R, Poder L. Uterine artery pseudoaneurysm in the setting of deep endometriosis: an uncommon cause of hemoperitoneum in pregnancy. Emerg Radiol. 2018;25(1):107-10. https://doi.org/10.1007/s10140-017-1560-0.

14. Zilberman A, Eisenberg V, Yoeli R, Soriano D, Sivan E, Golan G, et al. Uterine artery pseudoaneurysm in a pregnant patient with retrocervical endometriosis. J Minim Invasive Gynecol. 2020;27(5):1209-13. https://doi. org/10.1016/j.jmig.2020.03.010.

15. Laubach M, Delahaye T, Van Tussenbroek F, Debing E, De Catte L, Foulon W Uterine artery pseudo-aneurysm: diagnosis and therapy during pregnancy. J Perinat Med. 2000;28(4):321-5. https://doi.org/10.1515/JPM.2000.041

16. Beecham CT. Surgical treatment of endometriosis with special reference to conservative surgery in young women. J Am Med Assoc. 1949;139(15):971. https://doi.org/10.1001/jama.1949.02900320001001.

17. Kistner RW. Conservative management of endometriosis. J Lancet. 1959, 79(5):179-83.

18. Kistner RW. Endometriosis and infertility. Clin Obstet Gynecol. 1959;2(3):877-89. https://doi.org/10.1097/00003081-195902030-00023.

19. Navarro R, Poder L, Sun D, Jha P. Endometriosis in pregnancy. Abdom Radiol 2020;45:1741-1753. https://doi.org/https://doi.org/10.1007/s00261-02 0-02486-7, 6.

20. Frühauf $F$, Fanta $M$, Burgetová $A$, Fischerová $D$. Endometriosis in pregnancy - diagnostics and management. Endometrióza v těhotenství - diagnostika a management. Ceska Gynekol. 2019;84(1):61-7.

21. Leeners B, Damaso F, Ochsenbein-Kölble N, Farquhar C. The effect of pregnancy on endometriosis-facts or fiction? Human Reprod Update. 2018; 24(3):290-9. https://doi.org/10.1093/humupd/dmy004.

22. Manresa MC, Godson C, Taylor CT. Hypoxia-sensitive pathways in inflammation driven fibrosis. Am J Physiol Regul Integr Comp Physiol. 2014; 307(12):R1369-80. https://doi.org/10.1152/ajpregu.00349.2014.

23. Rossman F, D'Ablaing G III, Marrs RP. Pregnancy complicated by rupture endometrioma. Obstet Gynecol. 1983;62(4):519-21.

24. O'Leary SM. Ectopic decidualization causing massive postpartum intraperitonea hemorrhage. Obstet Gynecol. 2006;108:776-9.

25. Plaisier M. Decidualisation and angiogenesis. Best Pract Res Clin Obstet Gynaecol. 2011;25(3):259-71. https://doi.org/10.1016/j.bpobgyn.2010.10.011. 
26. Brosens IA, Fusi L, Brosens JJ. Endometriosis is a risk factor for spontaneous hemoperitoneum during pregnancy. Fertil Steril. 2009;92(4):1243-5. https:// doi.org/10.1016/j.fertnstert.2009.03.091.

27. Erikson DW, Chen JC, Piltonen TT, Conti M, Irwin JC, Giudice LC. Inhibition of epidermal growth factor receptor restores decidualization markers in stromal fibroblasts from women with endometriosis. J Endometriosis. 2014; 6(4):196-211. https://doi.org/10.5301/je.5000198.

28. Salazar GM, Petrozza JC, Walker TG. Transcatheter endovascular techniques for management of obstetrical and gynecologic emergencies. Tech Vasc Interv Radiol. 2009;12(2):139-47. https://doi.org/10.1053/j.tvir.2009.08.007.

29. Vedantham S, Goodwin SC, McLucas B, Mohr G. Uterine artery embolization: an underused method of controlling pelvic hemorrhage. Am J Obstet Gynecol. 1997;176(4):938-48. https://doi.org/10.1016/S0002-9378(97)70624-0.

30. Cornette J, van der Wilk E, Janssen NM, van der Weiden RMF, Jenninkens SFM, Pattynama $\mathrm{P}$, et al. Uterine artery pseudoaneurysm requiring embolization during pregnancy. Obstet Gynecol. 2014;123(2 Pt 2 Suppl 2):453-6.

31. Inversetti A, Giorgione V, Viganò P, Candiani M, A systematic review on endometriosis during pregnancy: diagnosis, misdiagnosis, complications and outcomes. Hum Reprod Update. 2016 https://doi.org/https://doi.org/1 0.1093/humupd/dmv045, 22, 1, 70, 103.

32. Zullo F, Spagnolo E, Saccone G, Acunzo M, Xodo S, Ceccaroni M, et al. Endometriosis and obstetrics complications: a systematic review and metaanalysis. Fertil Steril https://doi.org/https://doi.org/10.1016/j.fertnstert.2017. 07.019, 2017.

\section{Publisher's Note}

Springer Nature remains neutral with regard to jurisdictional claims in published maps and institutional affiliations.

Ready to submit your research? Choose BMC and benefit from:

- fast, convenient online submission

- thorough peer review by experienced researchers in your field

- rapid publication on acceptance

- support for research data, including large and complex data types

- gold Open Access which fosters wider collaboration and increased citations

- maximum visibility for your research: over $100 \mathrm{M}$ website views per year

At $\mathrm{BMC}$, research is always in progress.

Learn more biomedcentral.com/submissions 